\title{
ROLE OF WEATHER CONDITION ON THE DAILY APPEARANCE AND ADVERTISEMENT CALL INITIATION TIME OF POLYPEDATES LEUCOMYSTAX DURING BREEDING SEASON
}

\author{
D. $\operatorname{Roy}^{1}$, A. Choudhury ${ }^{2}$ and B. Borah ${ }^{1}$ \\ ${ }^{1}$ Department of Zoology, North Eastern Hill University, Shillong, Meghalaya 793022, India \\ ${ }^{2}$ Department of Statistics, Guwahati University, Assam, India \\ ${ }^{1}$ Email: debjaniroy39@hotmail.com
}

\begin{abstract}
Reports on amphibian breeding biology have emphasized on the role of either temperature or rainfall or both as the regulating factor for the initiation of reproductive activity. The result of the present study clearly indicates that once reproductive activity is initiated at the onset of rains, an overcast sky with high humidity plays a greater role than temperature or heavy rainfall during breeding season on Polypedates leucomystax.
\end{abstract}

\section{Keywords}

Call initiation time, Polypedates leucomystax, reproductive activity, weather condition

\section{Introduction}

Annual breeding activity of amphibians in tropical and temperate regions is influenced by climatic factors. Literature on breeding activity for various species from these two regions show that breeding activity is governed by either a single factor - temperature (Briggs, 1987; Fukuyama \& Kusano, 1992), rainfall (Ritke et al., 1992; Donnelly \& Guyer, 1994), moisture (Doreas \& Foltz, 1991; Moreira \& Barreto, 1997), wind (Robertson, 1986) or a combination (Lizana et al., 1994; Moreira $\&$ Barreto, 1997). One factor that is common is the rainy season, which is always associated with the amphibian breeding activity (Aichinger, 1987). Although rainfall is associated with the breeding migration or onset of breeding in some species, it seems to have less influence once the breeding starts (Okuno, 1985). Thus, majority of the works focus on factors affecting the onset of breeding or breeding migration, rather than activity throughout the breeding season. In order to understand the reproductive behaviour of anurans, it is essential to evaluate which factor affects the activities in reference to the geographical location of the study site.
The emergence pattern and initiation of vocalization in relation to climatic factors was studied for Polypedates leucomystax in Guwahati, India $\left(200 \mathrm{~m} ; 91.5^{\circ} \mathrm{E} \& 26.1^{\circ} \mathrm{N}\right)$ during breeding period in 1998 and 1999. Although India is largely a tropical country, Guwahati has temperate type of climate, with cool mountains in close proximity to warm lowlands. The reproductive activity is initiated with the onset of rainy season. During this period, there are dry hot days with clear sky, low humidity and no rainfall - categorized as sunny days; days with cloud cover, high humidity and light rainfall - categorized as cloudy days; and days with heavy rainfall and relatively high humidity categorized as rainy days. A comparative study between the effect of temperature and humidity was done to find out whether both parameters are equally important or one of them is more significant than the other.

\section{Methodology}

Polypedates leucomystax is widely distributed in eastern India. The frogs were found mostly perched on creepers, which entwine bamboos, fencing or on tall grass near the vicinity of water. They were found in groups of 10-22 males and two to four females. Four groups were observed around the pond measuring approximately $24 \times 15 \times 2 \mathrm{~m}$ located inside a private fish farm from March to late August during 1998 and 1999. Observations were recorded daily from 1630 hours. Torchlight, headlamps, mechanical counters and watches were used to locate, count the number of males and females and record advertisement call initiation time. Weather condition, air temperature and atmospheric humidity were recorded daily. Although temperature and humidity were recorded on all days beginning from March to August during 1998 and 1999, the data were tabulated only for those days on which the frogs appeared and advertised. Thus there were 115 observation days.

\section{Results}

A. Effect of weather on the appearance of males and females: In course of study, it became evident that appearance of males 
and females was dependent on weather condition. In order to find the dependence pattern, the data for the appearance of males and females in the four study groups for 1998 and 1999 were classified according to the weather conditions as rainy, cloudy and sunny (Table 1 ). Table 1 , shows that there is a significant difference between the appearance number of males and females on rainy, cloudy and sunny days. The appearance numbers for both the sexes showed similar trend - maximum number on rainy and minimum number on sunny days, which was also proved by using statistical test (t-test).

Since the appearance of both the sexes was found to be weather dependent, we next ascertained how the appearance was dependent on the two vital factors - temperature and humidity (Table 2). Correlation analysis between the number of frogs and different temperatures during rainy, cloudy and sunny days showed no significant results even at $\mathrm{p}<0.05$ and $\mathrm{p}<0.01$ (Table $3)$. This was expected since there was hardly any temperature difference $\left( \pm 4^{\circ} \mathrm{C}\right)$ during the study period.

The correlation coefficient (by t-test) between humidity and appearance of male (0.6) and female (0.4) was significant. Relationship between number of frogs (males $\&$ females) and humidity by regression equation was $\mathrm{y}=7.064+0.26152 \mathrm{x}$ for males and $y=-1.564+0.04313 x$ for females. For both the sexes the slope coefficient was at $5 \%$ probability level, thereby supporting the hypothesis that humidity and number of appearance of males and females were correlated.

Table 1. Number of male and female P. leucomystax in 1998 and 1999

\begin{tabular}{lllllll}
\hline & \multicolumn{3}{c}{ No. of males } & \multicolumn{3}{c}{ No. of females } \\
& Rainy & Cloudy & Sunny & Rainy & Cloudy & Sunny \\
\hline 1998 & & & & & & \\
March & 30 & 22 & 11 & 1 & 0 & 0 \\
Appril & 60 & 42 & 31 & 12 & 6 & 3 \\
May & 68 & 51 & 40 & 15 & 8 & 5 \\
June & 55 & 37 & 35 & 8 & 5 & 1 \\
July & 40 & 23 & 15 & 4 & 1 & 0 \\
August & 23 & 13 & 9 & 0 & 0 & 0 \\
1999 & & & & & & \\
March & 30 & 20 & 9 & 0 & 1 & 0 \\
April & 56 & 32 & 22 & 10 & 5 & 2 \\
May & 69 & 44 & 31 & 13 & 7 & 5 \\
June & 56 & 34 & 21 & 6 & 3 & 1 \\
July & 35 & 22 & 13 & 6 & 1 & 0 \\
August & 20 & 12 & 7 & 0 & 0 & 0 \\
\hline
\end{tabular}

Table 2. Temperature and humidity on rainy, cloudy and sunny days in 1998 and 1999

\begin{tabular}{|c|c|c|c|c|c|c|}
\hline & & Tempera & ture & & Humidity & \\
\hline & Rainy & Cloudy & Sunny & Rainy & Cloudy & Sunny \\
\hline 1998 & & & & & & \\
\hline March & 24 & 25 & 27 & 69 & 51 & 40 \\
\hline April & 28.9 & 29 & 30.1 & 62.3 & 59.5 & 63 \\
\hline May & 30.6 & 31 & 32.4 & 64.1 & 62 & 46.6 \\
\hline June & 33.8 & 34 & 36.7 & 71.2 & 62 & 42 \\
\hline July & 32.9 & 35 & 36.4 & 73.7 & 54.3 & 40.7 \\
\hline August & 31.3 & 32 & 35.7 & 70.7 & 52 & 40.7 \\
\hline 1999 & & & & & & \\
\hline March & 23.5 & 25 & 25.8 & 68.5 & 53 & 43.4 \\
\hline April & 28.5 & 29.4 & 30.1 & 63.5 & 54 & 43.4 \\
\hline May & 31.5 & 32.1 & 33.6 & 70.5 & 54.6 & 42.6 \\
\hline June & 33.7 & 34.6 & 35.6 & 69.4 & 54.6 & 41.1 \\
\hline July & 33.1 & 35.1 & 36.1 & 70.1 & 54.3 & 40.4 \\
\hline August & 32.8 & 34.5 & 34.9 & 68.7 & 55 & 40.4 \\
\hline
\end{tabular}

\section{B. Effect of weather on call time:}

Having found the dependence of the number and appearance of the males and females on humidity, tests were performed to work out the effect of humidity on the initiation of the first advertisement call timing for the four groups. To ensure easier analysis the first call time was shifted to 1745 hours for all calls, i.e. if the first advertisement call was recorded at 1730 hours it was recorded as -15 . Shifting all data points, the correlation coefficient between humidity and first call initiation time was analysed. The r-value was high -0.68 . The negative sign was significant, indicating that the relationship works in opposite direction, higher the humidity earlier the first call initiation time. To investigate this phenomenon in depth, the 115 observation days for 1998 and 1999 were dichotomized as humid, when the humidity level was $70 \%$ or more and for non-humid condition the humidity level at $69 \%$ or less. The first call timings for humid days were $\mathrm{n}=19, \mathrm{x}=-1.5789, \delta=252.77$ and non-humid days were $\mathrm{n}=96, \mathrm{x}=-13.22917, \delta=154.156$. To examine the mean values to be significantly different, t-test for testing differences of means were done, value being 4.48 significant at $5 \%$ probability level. The average call time for humid days was $-8.5 \mathrm{~min}$., i.e. on average the first call on humid days was heard at $1745 \mathrm{hr}-8.5 \mathrm{~min}=1736 \mathrm{hr}$. The first call time for non-humid days was $+7.5 \mathrm{~min}$., i.e. on average the first call on non-humid days were heard at $1745 \mathrm{hr}+7.5 \mathrm{~min}=1752 \mathrm{hr}$. A t-test for testing significance of difference between call times of humid and nonhumid days gave a value $8.5 \%$, which is highly significant at 
Table 3. Correlation values for number of frogs under different weather conditions

\begin{tabular}{lllllll}
\hline \multicolumn{6}{c}{ Rainy $\left(24^{\circ}-34^{\circ} \mathrm{C}\right)$} & \multicolumn{4}{l}{ Cloudy $\left(25^{\circ}-36^{\circ} \mathrm{C}\right)$} & \multicolumn{3}{l}{ Sunny $\left(25^{\circ}-37^{\circ} \mathrm{C}\right)$} \\
\multicolumn{1}{c}{ Male } & Female & Male & Female & Male & Female \\
\hline Group 1 & & & & & & \\
1998 & 0.269 & 0.481 & 0.066 & -0.056 & 0.023 & -0.354 \\
1999 & 1.08 & 0.395 & 0.128 & 0.066 & 0.356 & 0.161 \\
Group 2 & & & & & & \\
1998 & 0.36 & 0.356 & 0.11 & 0.067 & -0.018 & -0.351 \\
1999 & -1.11 & 0.218 & 0.142 & 0.411 & 0.225 & 0.092 \\
Group 3 & & & & & & \\
1998 & 0.342 & 0.126 & 0 & 0.101 & -0.014 & -0.081 \\
1999 & 0.264 & 0.154 & 0.081 & -0.202 & 0.133 & 0.112 \\
Group 4 & & & & & & \\
1998 & 0.106 & -0.039 & -0.126 & 0.273 & -0.182 & -0.374 \\
1999 & -0.037 & 0.231 & 0.398 & -0.337 & -0.176 & 0.133 \\
\hline
\end{tabular}

$5 \%$ probability level. Hence, it is evident that the first call time does differ between humid and non-humid days. In fact, we can accept the one-sided alternative hypothesis and conclude that the first call on humid days is heard significantly earlier than non-humid days. On an average the first call is about -8.5 $-7.5=16$ min earlier on humid than non-humid days. The relationship between first call and temperature was also tested and was found to be weak $(\mathrm{r}=0.3)$.

\section{Discussion}

Anuran breeding biology is influenced by climatic factors like temperature and rainfall or a combination of these, both for tropical and temperate species (Duellman \& Treub, 1986; Beebee, 1995). Some studies suggest that rainfall can be an important abiotic factor to initiate reproductive activity (Ritke et al., 1992; Donnelly \& Guyer, 1994; Barreto \& Andrade, 1995). Increased activity with rainfall might be that the moist soil condition acts as cue indicating that conditions are satisfactory for initiating breeding activity, to travel overland to ambient breeding ponds. Precipitation or atmospheric humidity is also strongly correlated with number of individuals that reproduce (Moreira \& Barreto, 1997). High moisture content may increase the possibility that the frogs could carry on their breeding activity longer without fear of desiccation.

The results of the present study clearly indicate that weather conditions plays a significant role on the breeding biology of $P$. leucomystax in India. There was significant difference between the number of males and females appearing on rainy, cloudy and sunny days. Since the appearance of frogs was found to be weather dependent, tests were performed to ascertain the dependence pattern. No correlation was found between appearance number and temperature but appearance number showed strong correlation with humidity.

As the number of appearance of frogs was found to be influenced by humidity, so did call initiation time. Higher the atmospheric humidity, earlier the call initiation time. The call initiation time varied significantly between humid and non-humid days. A model was worked out, which predicted that calls could be heard 16 min earlier on humid days in comparison to nonhumid days. Temperature was found to be weakly correlated with call initiation time.

The study clearly demonstrated that humidity plays a greater role than temperature, once the breeding activity starts with the onset of rains in the breeding biology of P. leucomystax in northeastern India.

\section{References}

Aichinger, M. (1997). Annual activity of anurans in a seasonal neotropical environment. Oecologia (Berl) 71: 583-592.

Barreto, L. and G.V. Andrade (1995). Aspects of reproductive biology of Physalaemus cuvieri (Anura: Leptodactylidae) in northeastern Brazil. Amphibia-Reptilia 16: 67-76.

Beebee, T. (1995). Amphibian breeding and climate. Nature 374: 219-220.

Briggs, J.L.Sr. (1987). Breeding biology of the cascade frog, Rana cascade, with comparisons to $R$. aurora and R. pretiosa. Copeia 241245.

Donnelly, M.A. and C. Guyer (1994). Pattern reproduction and habitat use in an assemblage of Neotropical hylid frogs. Oecologia 98 : 291-302.

Doreas, M.E. and K.D. Foltz (1991). Environmental effects on anuran advertisement calling. American Zoologist 31(5): 111A.

Duelleman, W.E. and L. Treub (1986). Biology of Amphibians. McGraw Hill, New York.

Fukuyama, K. and T. Kusano (1992). Factors affecting breeding activity in a stream-breeding frogs, Buergeria buergeri. Journal of Herpetogy 72: 23-31.

Lizana, M.R. Marquez and R. Martin-Sanchez (1994). Reproductive biology of Pelobates cultripes (Anura: Pelobatidae) in Central Spain. Journal of Herpetology 28: 19-27.

Moreira, G. and L. Barreto (1997). Seasonal variation in nocturnal calling activity of a savanna anuran community in Central Brazil. Amphibia-Reptilia 18: 49-57.

Okuno, R. (1985). Studies on natural history of the Japanese toad, Bufo japonicus japonicus VIII. Climatic factors influencing the breeding activity. Japanese Journal of Ecology 35: 527-535.

Ritke, M.E., J.G. Babb and M.K. Ritke (1992). Temporal patterns of reproductive activity in the gray treefrog (Hyla chrysocelis). Jounal of Herpetology 26: 111-114.

Robertson, J.G.M. (1986). Male territoriality, fighting and assessment of fighting ability in the Australian frog Uperolia rugosa. Animal Behaviour 34: 763-772. 